\title{
Endoscopic submucosal dissection of a huge esophageal atypical lipomatous tumor (well-differentiated liposarcoma) with a 4-year recurrence-free survival
}

A 35-year-old man complained of dull pain after food intake. His medical history and findings from physical examinations and laboratory tests were unremarkable. Standard esophagogastroduodenoscopy revealed a huge mass in the cervical esophagus. On endoscopy, the sausage-like pedunculated tumor protruded into the lumen ( $\mathbf{F i g . 1}$ ). Chest computed tomography (CT) scan

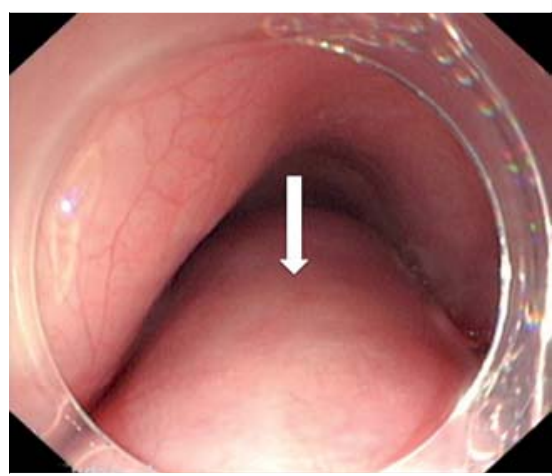

Fig. 1 Endoscopic view of a huge mass (arrow) in the cervical esophagus of a 35-year-old man who complained of dull pain after food intake. showed a large mass that was well-circumscribed, intraluminal, and heterogeneous (fatty density in the upper section and parenchymal density in the lower part) ( $\triangleright$ Fig. 2). The mass was located between the T1 to T8 levels and connected to the posterior wall of the esophagus.
Endoscopic submucosal dissection (ESD) was performed successfully to treat this patient ( $\vee$ Fig. 3 , $\vee$ Video 1 ). The submucosal injection and initial mucosal incision ( $\triangleright$ Fig. $\mathbf{3}$ b) were done at the base of the mass, $18 \mathrm{~cm}$ from the incisors, using a Hybrid Knife (I-type; Erbe, Tübingen,

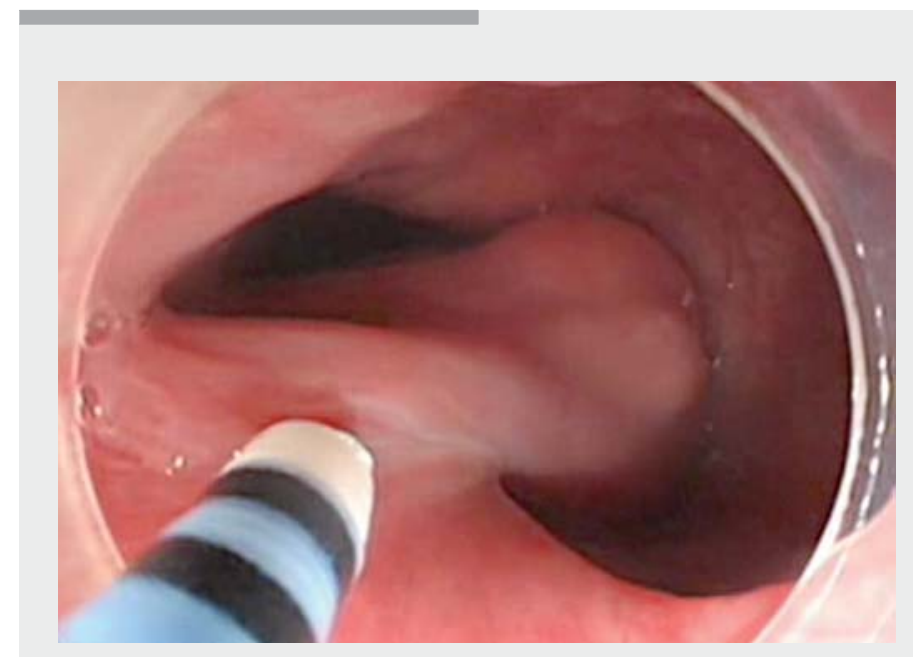

Video 1 Endoscopic submucosal dissection of a huge esophageal atypical lipomatous tumor (well-differentiated liposarcoma) in a 35-year-old man.
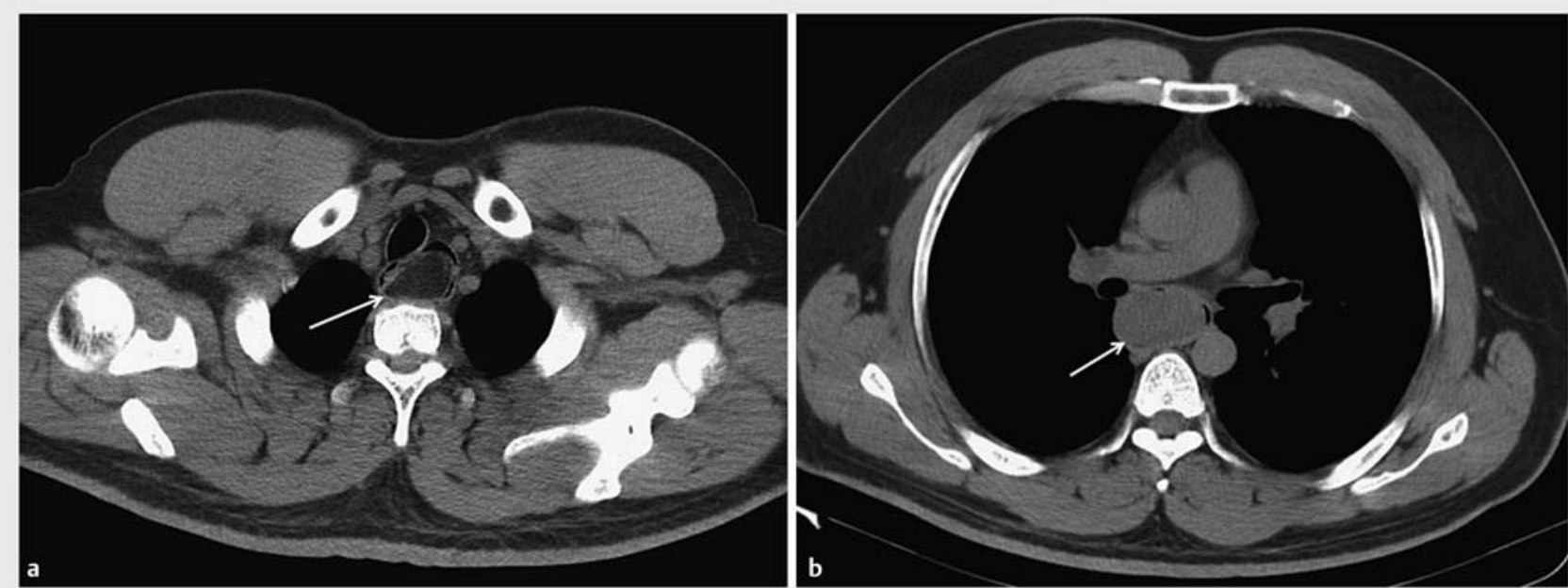

- Fig. 2 Computed tomography (CT) scan showed a large, well-circumscribed, intraluminal, heterogeneous mass located in the posterior wall of the esophagus between the T1 to T8 levels. a Fatty density (arrow) in the upper section of the mass. b Parenchymal density (arrow) in the lower part of the mass. 

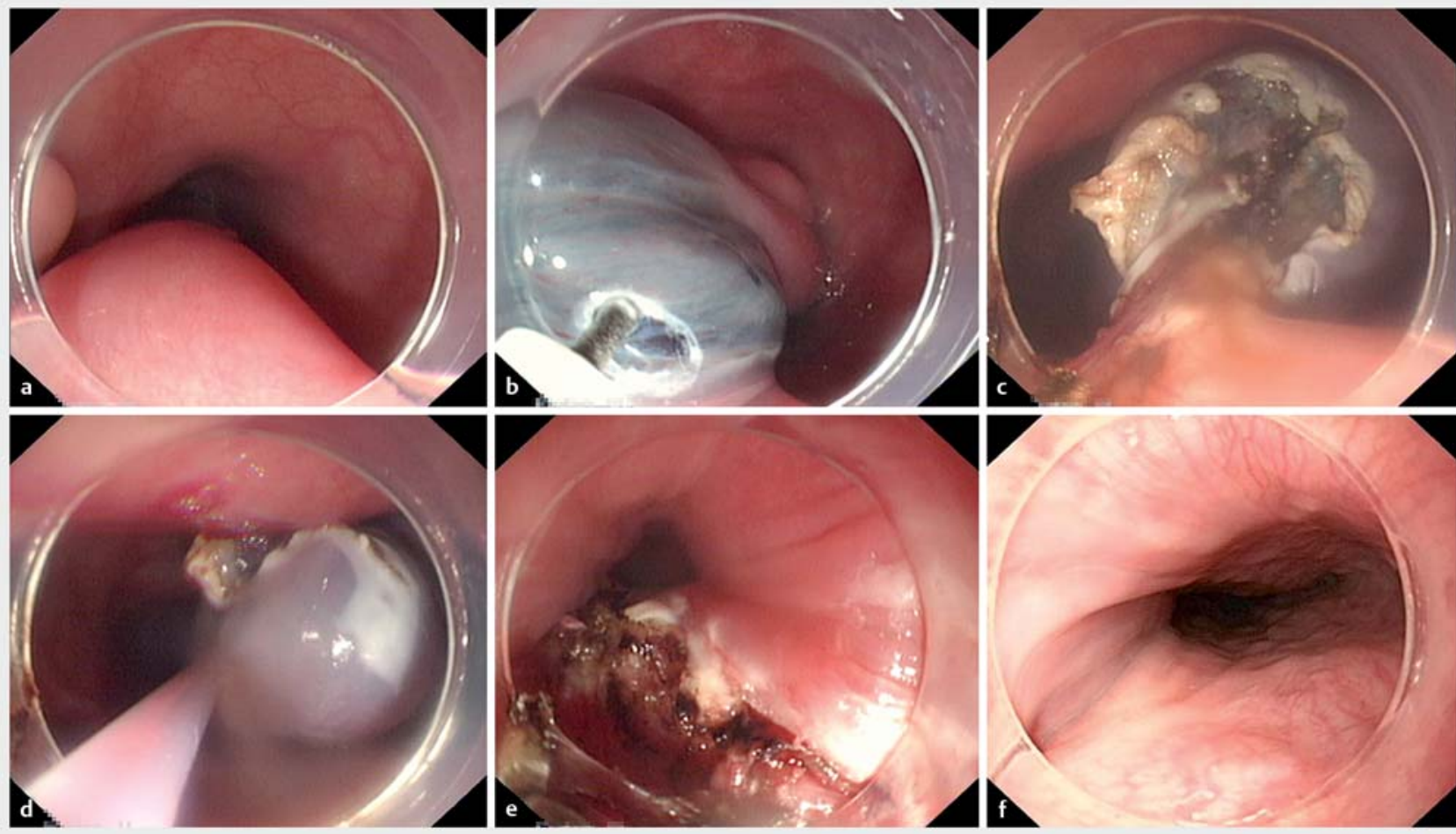

- Fig. 3 The endoscopic submucosal dissection (ESD) procedure. a Endoscopic view of the huge submucosal tumor. b Submucosal injection and mucosal incision at the base of the submucosal tumor. c Resection of the submucosal tumor. d Removal of the submucosal tumor with a snare. $\mathbf{e}$ The wound after hemostasis. $\mathbf{f}$ Endoscopic view of the esophagus after 3 months follow-up with no residual tumor or recurrence.

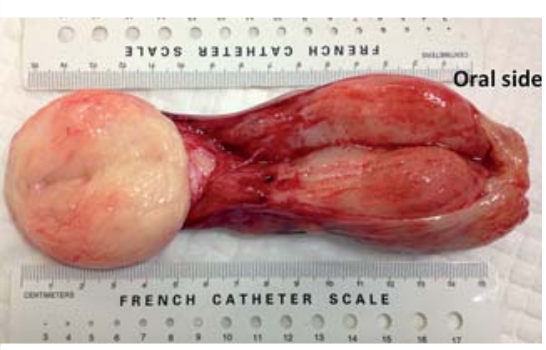

Fig. 4 Macroscopic appearance of the huge esophageal submucosal tumor.

Germany). Then submucosal dissection was performed from the oral side to anal side after complete incision of the huge mass ( $\triangleright$ Fig. $3 \mathbf{c}$ ), while submucosal injections were frequently repeated to secure an appropriate lifting of the mucosal layer from the muscle layer. En bloc resection was achieved by ESD technique, then a snare (SD-230U-20, Olympus) was used to retrieve the resected specimen ( $\triangleright$ Fig.3d), all visible exposed vessels on the wound were coagulated by hemostatic forceps (FD-410LR, Olympus) (\$ Fig. 3 e).
The resected tumor was $16.0 \times 5.5 \times$ $4.0 \mathrm{~cm}$ in size and $124 \mathrm{~g}$ in weight ( $\triangleright$ Fig. 4). Pathological examination, confirmed by immunohistochemical staining, indicated the tumor was an atypical lipomatous tumor (also termed "well-differentiated liposarcoma”) (ฉ Fig.5). The postoperative period was uneventful and the patient was discharged on postoperative day 2 .

The patient was scheduled for the first endoscopic follow-up 3 months later ( Fig.3f), and annually thereafter. After 4 years, there has been no evidence of any residual tumor or recurrence. This case presents a successful attempt to treat an esophageal atypical lipomatous tumor by ESD with a 4-year disease-free and recurrence-free survival.

Atypical lipomatous tumors (well-differentiated liposarcomas) are very rare in the esophagus. Fewer than 20 cases have been reported [1] with the dominant location being the cervical esophagus. Reported methods of treatment included transthoracic esophagectomy, transoral resection, thoracoscopic eso- phagectomy or even total esophagectomy. The predominant type of the tumor in the esophagus was polypoid and seldom transmural [1]. This provides a good chance for endoscopic removal of the tumor. Since this type is a low grade malignant mesenchymal neoplasm with a high propensity to local recurrence and the potential to dedifferentiate to higher grades over time [2], long-term follow-up is warranted for this case.

Endoscopy_UCTN_Code_CCL_1AB_2AC_3AB

Competing interests

There is no conflict of interest to declare for Drs. Ping-Hong Zhou, Ming-Yan Cai, and JiaXin Xu. 

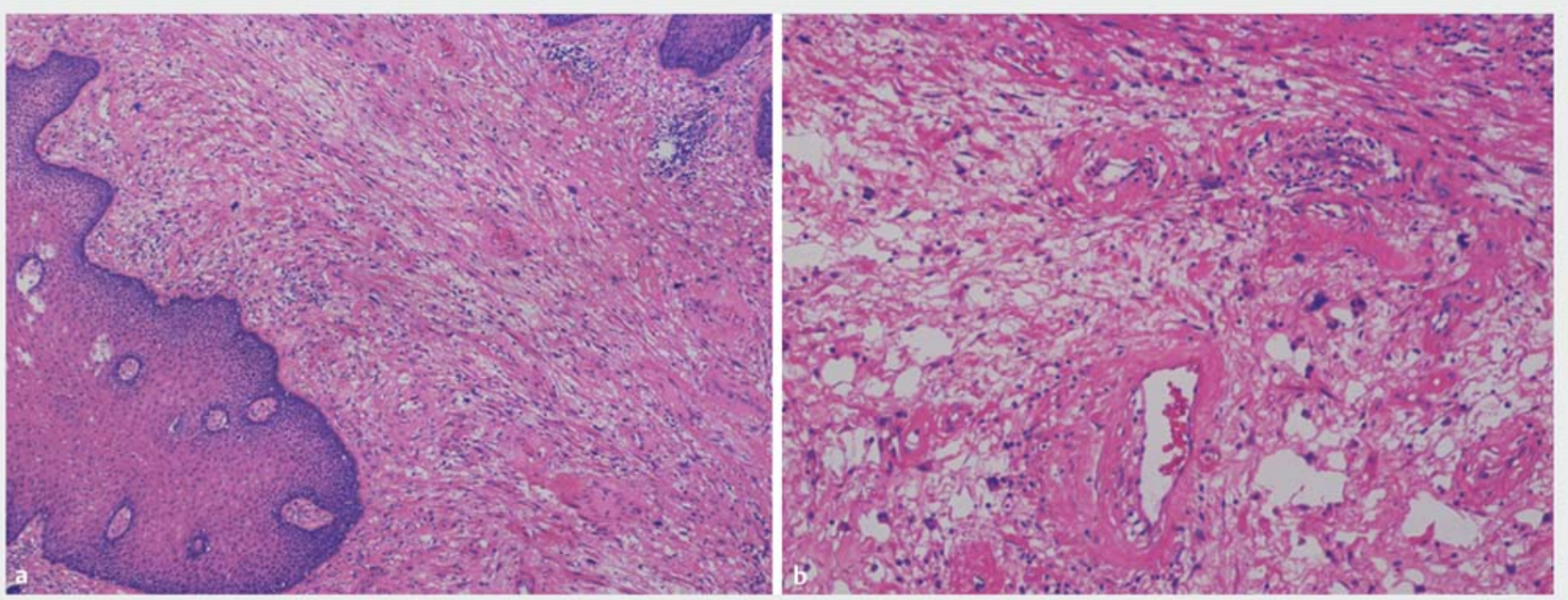

Fig. 5 Pathologic evaluation of the resected tumor. a The tumor was covered by normal squamous epithelium. b Histologically, the tumor was composed of a well-differentiated lipomatous component adjacent to scattered bizarre spindle cells (hematoxylin-eosin stain).

\section{The Authors}

\section{Ming-Yan Cai", Jia-Xin Xu*, Ping-Hong Zhou}

Endoscopy Center and Endoscopy Research Institute, Zhongshan Hospital, Fudan University, Shanghai, China

\section{Corresponding author}

\section{Ping-Hong Zhou, MD}

Endoscopy Center and Endoscopy Research Institute, Zhongshan Hospital, Fudan University, 180 FengLin Road, Shanghai, 200032, P. R. China

Fax: +86-21-64041990

zhou.pinghong@zs-hospital.sh.cn

\footnotetext{
* These authors contributed equally to this work.
}

\section{Acknowledgment}

This study was supported by the National Natural Science Foundation of China (81470811, Dr. P.-H. Zhou), (81301760, Dr. M.-Y. Cai).

\section{References}

[1] Boni A, Lisovsky M, Dal Cin P et al. Atypical lipomatous tumor mimicking giant fibrovascular polyp of the esophagus: report of a case and a critical review of literature. Hum Pathol 2013; 44: 1165-1170

[2] Mavrogenis AF, Lesensky J, Romagnoli C et al. Atypical lipomatous tumors/well-differentiated liposarcomas: clinical outcome of 67 patients. Orthopedics 2011; 34: e893898

\section{Bibliography}

DOI https://doi.org/10.1055/s-0043-114405

Published online: 18.7.2017

Endoscopy 2017; 49: E237-E239

(c) Georg Thieme Verlag KG

Stuttgart · New York

ISSN 0013-726X

\section{ENDOSCOPY E-VIDEOS}

https://eref.thieme.de/e-videos

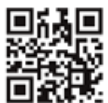

Endoscopy E-Videos is a free access online section, reporting on interesting cases and new techniques in gastroenterological endoscopy. All papers include a high quality video and all contributions are freely accessible online.

This section has its own submission website at

https://mc.manuscriptcentral.com/e-videos 